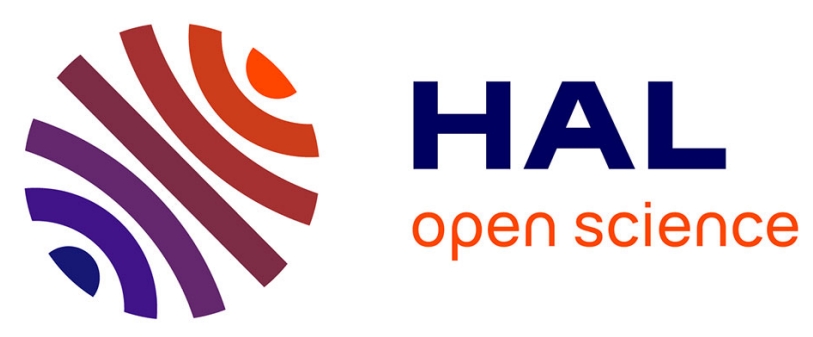

\title{
Molecular epidemiology of invasive and non-invasive group B Streptococcus circulating in Serbia
}

Ina Gajic, Céline Plainvert, Dusan Kekic, Nicolas Dmytruk, Vera Mijac, Asmaa Tazi, Philippe Glaser, Lazar Ranin, Claire Poyart, Natasa Opavski

\section{To cite this version:}

Ina Gajic, Céline Plainvert, Dusan Kekic, Nicolas Dmytruk, Vera Mijac, et al.. Molecular epidemiology of invasive and non-invasive group B Streptococcus circulating in Serbia. International Journal of Medical Microbiology, 2019, 309 (1), pp.19-25. 10.1016/j.ijmm.2018.10.005 . pasteur-03108157

\section{HAL Id: pasteur-03108157}

\section{https://hal-pasteur.archives-ouvertes.fr/pasteur-03108157}

Submitted on 13 Jan 2021

HAL is a multi-disciplinary open access archive for the deposit and dissemination of scientific research documents, whether they are published or not. The documents may come from teaching and research institutions in France or abroad, or from public or private research centers.
L'archive ouverte pluridisciplinaire HAL, est destinée au dépôt et à la diffusion de documents scientifiques de niveau recherche, publiés ou non, émanant des établissements d'enseignement et de recherche français ou étrangers, des laboratoires publics ou privés.

\section{(1) (1) $\$$}

Distributed under a Creative Commons Attribution - NonCommercial - NoDerivatives 44.0 


\title{
Molecular epidemiology of invasive and non-invasive group B Streptococcus circulating in Serbia
}

\author{
Ina Gajic ${ }^{\mathrm{a}, \mathrm{b}}$, Celine Plainvert ${ }^{\mathrm{c}, \mathrm{d}, \mathrm{e}, \mathrm{f}, \mathrm{g}, \mathrm{h}, \mathrm{i}}$, Dusan Kekic ${ }^{\mathrm{a}, \mathrm{b}}$, Nicolas Dmytruk ${ }^{\mathrm{c}, \mathrm{d}, \mathrm{e}}$, Vera Mijac ${ }^{\mathrm{a}}$ \\ b, Asmaa Tazi ${ }^{\text {d, e, f, g, h, i, Philippe Glaser }}{ }^{\mathrm{j}}$, Lazar Ranin ${ }^{\mathrm{a}, \mathrm{b}}$, Claire Poyart ${ }^{\mathrm{c}}$, d, e, f, g, h, i , Natasa \\ Opavski, $^{\mathrm{a}, \mathrm{b}}$
}

${ }^{a}$ Institute of Microbiology and Immunology, Medical Faculty, University of Belgrade, Dr Subotica 1, 11000 Belgrade, Serbia,

${ }^{\mathrm{b}}$ National Reference Laboratory for Streptococci, Dr Subotica 1, 11000 Belgrade, Serbia,

${ }^{\mathrm{c}}$ Service de Bactériologie, Assistance Publique-Hôpitaux de Paris, Hôpitaux Universitaires

Paris Centre Site Cochin, 27, rue du Faubourg-Saint-Jacques, 75014 Paris, France,

${ }^{\mathrm{d}}$ Centre National de Référence des Streptocoques, 27, rue du Faubourg-Saint-Jacques, 75014 Paris France,

${ }^{\mathrm{e}}$ DHU Risques et Grossesse, Assistance Publique-Hôpitaux de Paris, 3 Avenue Victoria, 75004 Paris, France,

${ }^{\mathrm{f}}$ Université Paris Descartes, Sorbonne Paris Cité, 12 Rue de l'École de Médecine, 75006 Paris, France,

g INSERM U 1016, Institut Cochin, Team 'Barriers and Pathogens', 27, rue du Faubourg-SaintJacques, 75014 Paris, France,

${ }^{\text {h }}$ CNRS UMR 8104, 27, rue du Faubourg-Saint-Jacques, 75014 Paris, France,

${ }^{\mathrm{i}}$ Unité de Biologie des Bactéries Pathogènes à Gram-positif, CNRS ERL3526, 25-28 Rue du Dr Roux, 75015 Paris, France,

${ }^{\mathrm{j}}$ Institut Pasteur, Unité de Biologie des Bactéries Pathogènes à Gram Positif, 25-28 Rue du Dr Roux, 75015 Paris, France.

Corresponding author:

Natasa Opavski

Institute of microbiology and immunology, Medical Faculty, University of Belgrade, Serbia Doktora Subotica starijeg 1, 11000 Belgrade, Serbia

Email address: natasaopavski@gmail.com

Telephone number: +381113643378

Fax number: +381113643360 


\begin{abstract}
Streptococcus agalactiae (group B Streptococcus, GBS) remains the leading cause of invasive diseases in neonates and an important cause of infections in the elderly. The aim of this study was to access the prevalence of GBS genito-rectal colonisation of pregnant women and to evaluate the genetic characteristics of invasive and non-invasive GBS isolates recovered throughout Serbia.

A total of 432 GBS isolates were tested for antimicrobial susceptibility, capsular polysaccharide (CPS) types and the presence of the $h v g A$ gene. One hundred one randomly selected isolates were further characterized by clustered regularly interspaced short palindromic repeats (CRISPRs) analysis and/or multilocus sequence typing (MLST).

The prevalence of GBS colonization in pregnant women was 15\%. Overall, six capsular types ( $\mathrm{Ia}, \mathrm{Ib}$, II to V) were identified, the most common being III (32.2\%) and V (25.2\%). The hiper-virulent clone type III/ST17 was present in $43.1 \%$ and $6.3 \%(\mathrm{p}<0.05)$ of paediatric and adults isolates, respectively. Comparative sequence analysis of the CRISPR1 spacers content indicated that a few clones comprised the vast majority of the tested GBS isolates. Thus, it was estimated that dominant clones recovered from infants were CPS III/ST17 in late-onset infections $(19 / 23 ; 82.6 \%)$, and Ia/ST23 in early-onset disease (44.4\%). Conversely, genotype CPS V/ST1 was the most prevalent in adults $(4 / 9 ; 25.4 \%)$. All isolates were susceptible to penicillin. Macrolide resistance $(23.1 \%)$ was strongly associated with the ermB gene and constitutive resistance to clindamycin $(63.9 \%)$. The majority of strains was resistant to tetracycline $(86.6 \%)$, mostly mediated by the tetM gene $(87.7 \%)$. GBS isolates of CPS V/ST1 and CPS III/ST23 were significantly associated with macrolide and tetracycline resistance, respectively.

In conclusion, hyper-virulent CPS III/ST17 and V/ST1 were recognized as dominant GBS clones in this study.
\end{abstract}

Keywords: Streptococcus agalactiae, capsular type, hyper-virulent clone ST17, neonates, pregnant women, CRISPR 


\section{Introduction}

Streptococcus agalactiae (group B Streptococcus, GBS) is one of the leading causes of neonatal invasive infection (Edwards et al., 2011; Imperi et al., 2011). Two distinct clinical syndromes have been recognized in neonates: early-onset disease (EOD), which occurs within the first six days of life and is mostly associated with bacteraemia, and late-onset disease (LOD), which affects infants between 7 and 89 days old and is frequently complicated by meningitis (Edwards et al., 2011). The pathogenesis of infant infections is based on GBS colonization of the maternal genital tract and subsequent intrapartum or peripartum contamination of the neonate through contaminated vaginal secretions or infected amniotic fluid (Edwards et al., 2011). It is estimated that GBS can be isolated from the genitourinary and gastrointestinal tracts of up to $35 \%$ of healthy adults (Bliss et al., 2002). In contrast to EOD, LOD might be acquired either vertically during parturition or by horizontal transmission during the perinatal period from various environmental sources. The worldwide incidence of GBS disease in infants aged 0-89 days is estimated to be $0.53 / 1000$ live births with a mortality rate of 9.6\% (Edmond et al., 2012). Consequently, a number of countries have implemented preventive strategies based on maternal screening for GBS colonization, and intrapartum antibiotic prophylaxis (IAP) for colonized women (CDC, 2010). GBS is also an increasingly important cause of infection in the elderly and in patients with chronic underlying conditions (Edwards and Baker, 2005).

Characterization of GBS isolates relies on their capsular polysaccharide (CPS) serotype, of which ten have been recognized up to now (Ia, Ib and II-IX) (Slotved et al, 2007). Alongside capsular typing, DNA-based typing methods are now extensively used for genetic lineage evaluation of GBS isolates. Multilocus sequence typing (MLST) has been helpful in GBS population structure analysis, and investigation of virulence potential and tropism (Jones et al, 2003). It is well known that most GBS isolates can be assigned to a small number of clonal complexes (CCs). The most common CCs associated with invasive cases in infants are CC17, CC19, CC23, and CC1 (Jones et al., 2003). Among those, CC17 strains are considered 'hypervirulent' as they are responsible for the vast majority of meningitis and LOD cases (Jones et al., 2003; Poyart et al., 2008). Conversely, CC1, CC19, and CC23 appear to be dominant among colonized women (Jones et al., 2003).

Clustered regularly interspaced short palindromic repeats (CRISPRs) have been recently identified in most archaea and many bacteria (Sorek et al., 2008). CRISPR and CRISPR- 
associated genes (Cas) are an adaptive immune system to protect prokaryotes against foreign genetic elements, including bacteriophages, transposons, and plasmids (Barrangou and Marraffini, 2014). The CRISPR1 analysis represents a new and powerful means for precise population genomics studies of $S$. agalactiae. Perfect correlation between CRISPR1 diversity and MLST in GBS has been demonstrated recently (Lopez-Sanchez et al., 2012). All isolates of GBS are considered uniformly susceptible to $\beta$-lactams, with penicillin commonly being the first drug of choice for the prophylaxis and treatment of GBS infections.

the first drug of choice for the prophylaxis and treatment of GBS infections. In the case of beta-lactam allergy, the guidelines suggest the use of clindamycin/erythromycin or vancomycin as second-line agents. However, increased levels of erythromycin and clindamycin resistance have been reported worldwide (Gygax et al., 2006; Gherardi et al., 2007).

In Serbia, neither guidelines for the prevention of GBS invasive neonatal infections, nor an active surveillance of GBS diseases exist. Indeed, there is little data on the epidemiology of circulating GBS population. Therefore, the aims of this work were: $(i)$ to determine the prevalence of GBS recto-vaginal colonisation of pregnant women (ii) to investigate the molecular epidemiology of GBS in Serbia by determining the capsular types, STs and CRISPR1 profiles and (iii) to determine the prevalence and genetic bases of antibiotic resistance.

\section{Material and methods}

Bacterial strains

A collection of 432 epidemiologically unrelated GBS isolates recovered throughout Serbia were included in this study. The GBS collection comprised children isolates $(n=51)$, strains of non-pregnant adults (genital $=190$; invasive $=6$ ), and vaginal-perianal strains obtained from pregnant women irrespective of gestation time $(n=185)$. Paediatric isolates and GBS strains recovered from non-pregnant adults were obtained from seven microbiological laboratories throughout Serbia, while GBS isolates of pregnant women were collected from patients attending two gynaecology and obstetrics clinics. All available invasive GBS were obtained from December 2009 to March 2016, while non-invasive GBS were isolated from January 2015 to October 2016.

A total of 1233 recto-vaginal swabs were collected from pregnant women during the third trimester of pregnancy. Briefly, anorectal specimens were placed in Amies transport medium 
(Copan, Italy) and immediately delivered to the microbiology laboratory, where they were transferred to $1 \mathrm{ml}$ selective Todd-Hewitt broth (Becton Dickinson, USA) supplemented with gentamicin $\left(8 \mu \mathrm{g} \mathrm{mL}^{-1}\right)$ and nalidixic acid $\left(15 \mu \mathrm{g} \mathrm{mL} \mathrm{m}^{-1}\right)$ and incubated for $18 \mathrm{~h}$ at $37^{\circ} \mathrm{C}$. Subcultures on chromID Strepto B (BioMerieux, France) and columbia blood agar with $5 \%$ sheep blood (BioMerieux, France) were incubated for $24 \mathrm{~h}$ at $37^{\circ} \mathrm{C}$. Invasive isolates were defined as GBS isolated from sterile sites (e.g., blood, cerebrospinal fluid, and joint fluid). Children were classified according to the GBS disease onset and age: 0-6 days as EOD, 7-180 days as LOD. GBS infections in children aged 180 days -5 years were uncommon and were grouped together.

Isolated GBS and the relevant patient information were submitted to the Serbian National Reference Laboratory for Streptococci.

GBS isolates were identified based on colony morphology, $\beta$-haemolysis, Gram staining, catalase test, and commercial GBS latex-agglutination assays (Slidex strepto B, bioMerieux, France). All isolates were identified by mass spectrometry MALDI-TOF (Matrix Assisted Laser Desorption Ionisation Time Of Flight) (Bruker TM) according to the manufacturer's recommendations at the French National Reference Laboratory for Streptococci (CNRStrep:https://www.cnr-strep.fr/) and further genotyped.

\section{Molecular characterization of GBS isolates}

Capsular typing of 423 GBS was performed by a multiplex PCR as described elsewhere (Poyart et al, 2007). Additionally, the $h v g A$ gene encoding a surface protein specific to the hyper-virulent ST17 clone was detected by real-time PCR (Lamy et al., 2006). In order to evaluate the genetic relatedness of the tested isolates, CRISPR1 analysis and/or MLST were performed for 101 out of 423 randomly selected strains. The CRISPR1 loci were amplified and sequenced as previously described (Lopez-Sanchez et al., 2012). For sequence analysis, the CRISPR1 loci were divided into direct repeats (DRs) and corresponding spacer sequences with CRISPRdb (http://crispr.u-psud.fr/crispr/) (Grissa et al., 2007). CRISPR profiles were assigned according to the spacers' content (spacers' number, order and type). Based on the previously published correlation between MLST and CRISPR1, the MLST profile was deduced from the CRISPR1 results for 90 strains (Lopez-Sanchez et al., 2012). MLST was performed for 11 strains for which atypical CRISPR1 profiles were obtained and for ten additional GBS to 
compare obtained STs. Seven housekeeping genes (adhP, pheS, atr, glnA, sdhA, glcK, and tkt) were amplified and sequenced as described elsewhere (Jones et al., 2003). The STs were determined by the S. agalactiae MLST website (http://pubmlst.org/sagalactiae/).

\section{Antimicrobial susceptibility tests}

Antimicrobial susceptibility profiles were determined by disk diffusion tests for penicillin, norfloxacin, vancomycin, rifampicin, erythromycin, clindamycin, gentamicin, kanamycin, chloramphenicol, and tetracycline. Penicillin MICs were determined for all isolates, while erythromycin and clindamycin MICs were evaluated for macrolide-resistant strains (E-test, BioMérieux, France). Antibiotic susceptibility testing was performed in accordance with the CLSI guidelines (CLSI, 2014). Macrolide resistance phenotypes were assigned as follows: constitutive cross-resistance to macrolides, lincosamides and streptogramin B (cMLS), inducible MLS (iMLS), or efflux-mediated (M) on the basis of the double-disk test, as previously described (Seppälä et al., 1993). Detection of macrolides, kanamycin and tetracycline resistance genes was performed by simplex or multiplex PCR as previously described (Poyart et al., 2003). In case of tetracycline resistance and absence of tet $M$, tet $O$, and tetL, additional genes were tested: tetK, tetT, tetS (Compain et al., 2014).

\section{Statistical analysis}

Statistical analysis was performed using $\chi^{2}$ and Fisher exact tests. Differences were considered statistically significant at $\mathrm{p}<0.05$. Genetic diversity was evaluated by calculating Simpson's index of diversity (ID) (Simpson, 1949).

\section{Results}

\section{Genetic diversity of GBS isolates}

A total of 432 non-related GBS isolates were genotypically analyzed (invasive: 51; noninvasive: 381 ). Clinical data are summarized in Table 1. Fifty-one invasive GBS (45 children and 6 adults isolates) were obtained from blood cultures $(n=44)$, cerebrospinal fluid $(n=4)$, and joint fluid $(n=3)$. The most common clinical diagnosis of invasive isolates was septicaemia $(86.3 \%)$, while meningitis (7.8\%) and arthritis (5.9\%) were far less frequent. Out of 45 invasive GBS obtained from children, 21 and 23 were responsible for EOD and LOD, respectively; one 
invasive paediatric GBS originated from a 5-year old child. All adults with invasive disease had bacteremia and were older than 60 years. Non-invasive GBS were isolated from recto-vaginal specimens of pregnant and non-pregnant patients $(n=375 ; 98.4 \%)$ and from colonized or infected infants $(n=6 ; 1.6 \%)$. A total of 185 out of 1233 tested pregnant women were colonised with GBS $(15 \%)$.

A CPS type was assigned to all GBS isolates. Overall, six capsular types (Ia, Ib, II to V) were identified, the most common being III (139/432; 32.2\%) and V (109/432; 25.2\%). CPS types VI to IX were not found in the tested population. The most common type among invasive isolates was III $(30 / 51 ; 58.8 \%)$, followed by Ia $(7 / 51 ; 13.7 \%)$, and V $(6 / 51 ; 11.8 \%)$. The most prevalent non-invasive types were III $(109 / 381 ; 29 \%)$ and V $(103 / 381 ; 27 \%)$, while the remaining types (Ia, Ib, II, and IV) accounted for $44 \%$ of isolates. CPS types Ia $(6 / 21 ; 29 \%)$ and V $(6 / 21 ; 29 \%)$ were predominant in EOD, whereas 20 out of 23 LOD were caused by CPS type III (87\%). The three remaining CPS types in LOD were Ia, Ib and IV. Overall, the $h v g A$ gene was present in 31 out of 432 GBS isolates (7.2\%). The vast majority of the $h v g A$ positive GBS were identified as CPS type III ( $n=29 ; 93.5 \%)$, while only two GBS were CPS type IV. Two out of three GBS strains isolated from infants with septic arthritis were CPS type III, one being the $h v g A$ gene positive. The remaining GBS isolate was CPS type IV. All three cases of arthritis were late-onset diseases. The hiper-virulent clone type III/ST17 was present in $43.1 \%$ and $6.3 \%(\mathrm{p}<0.05)$ of paediatric and adults isolates, respectively.

To further investigate the genetic relatedness among 101 randomly selected GBS isolates a CRISR1 analysis was performed. According to the specific spacers' content, a total of 87 CRISPR1 profiles were obtained. CRISPR1/MLST correlation and MLST analysis showed that the 101 GBS isolates belonged to 14 STs (Tables 2 and Fig. 1). ST17 and ST23 were the most prevalent types (25.7\% and 24.8\%, respectively), followed by ST1 (20.8\%), ST8 (8.9\%), ST19 (7.9\%), ST28 (3\%), and ST10 (2\%). Other STs, including ST2, ST3, ST4, ST6, and ST12, were identified in only one isolate each. The hyper-virulent ST17 clone represented $100 \%$ of the CPS III strains responsible for LOD. Overall, the ST17 prevalence was significantly higher in children than in adults (43.1\% vs. $6.3 \%, \mathrm{p}<0.05)$, and in LOD in comparison to EOD (87\% vs. $4.7 \%, \mathrm{p}<0.05)$. Simpson's index of diversity for particular CPS types is presented in Table 3. The highest homogeneity was seen in GBS strains of CPS III and V, particularly in genotypes III/ST17 and V/ST1. A total of 35 and 18 CRISPR1 profiles were detected for CPS III $(\mathrm{n}=44)$ 
and ST17 ( $\mathrm{n}=26)$ isolates, respectively. The highest diversity was seen for CPS types Ib, II and IV. STs diversity was higher among adults (ID =0.88) and EOD (ID=0.72) than in LOD $(\mathrm{ID}=0.13)$.

\section{Antimicrobial susceptibility testing}

All isolates were susceptible to penicillin (MICs range: 0.023-0.064 $\mathrm{mg} \mathrm{L}^{-1}$ ), vancomycin, norfloxacin, chloramphenicol, and rifampicin. The overall erythromycin and clindamycin resistance rates were $23.1 \%(n=100)$ and $21.3 \%(n=92)$, respectively. Macrolide resistance in invasive and non-invasive strains was $19.6 \%(\mathrm{n}=10)$ and $22.8 \%(\mathrm{n}=87)$, respectively. A slight increase in macrolide resistance among invasive GBS was observed during the study period. Hence, in 2009-2014 $(n=23)$ and 2015-2016 $(n=28)$ macrolide resistance of invasive GBS was $17.4 \%$ and $21.4 \%$, respectively $(\mathrm{p}<0.05)$. Among erythromycin-resistant isolates, $63.9 \%(\mathrm{n}=62)$ displayed the cMLS phenotype, $25.8 \%(n=25)$ the iMLS phenotype, and $10.3 \%(n=10)$ the $M$ phenotype. cMLS and iMLS phenotypes were associated with the presence of the ermB and ermA genes, respectively, whereas the $\mathrm{M}$ phenotype was related to the presence of the mefA gene. Two strains with cMLS phenotype harboured both ermB and mefA genes. The MICs of erythromycin and clindamycin were $\geq 256 \mathrm{mg} / \mathrm{L}$ in ermB-positive strains. In comparison, the erythromycin MIC was $\leq 16 \mathrm{mg} / \mathrm{L}$ in single $m e f A$-positive strains.

Eighty-six percent of the strains $(n=374 / 432)$ were phenotypically resistant to tetracycline. Among these strains, tet $M$, tetO and tetL accounted for $87.7 \%(\mathrm{n}=328), 12.8 \%(\mathrm{n}=48)$, and $0.3 \%$ $(n=1)$, respectively. A high proportion of tetracycline resistance was observed in both invasive $(96 \% ; n=49)$ and non-invasive $(85.3 \% ; n=325)$ isolates. The tet $M$ gene was in association with tet $O$ and tet $L$ in three strains and one strain, respectively. One tetracycline susceptible strain harboured tetM. All GBS strains with MLS phenotypes were co-resistant to tetracycline.

High-level resistance to kanamycin was detected in one strain which harboured the aphA-3, gene (CPS III/ST19/tetM/ermB).

The majority of erythromycin- $(n=97)$ and tetracycline-resistant (374) strains belonged to CPS types V (42/97; 43.3\% and 89/374; 23.8\%) and III (35/97; 36.1\% and 121/374; 32.4\%), respectively. Furthermore, a statistically significant association between CPS type V/ST1 and macrolide resistance as well as between CPS type III/ST23 and tetracycline resistance was observed $(\mathrm{p}<0.05)$. 


\section{Discussion}

Compared to the obtained prevalence of GBS colonisation of pregnant women (15\%), slightly higher rates were reported for European (21\%), African (29\%) and Asian women (13\%) who were at lower risk for GBS carriage (Walkenburg-van den Berg et al., 2006).

This is the first molecular epidemiological study on GBS isolates from Serbia. Even though a limited number of strains were included, our initial results revealed that four CPS types (Ia, II, III, and V) accounted for more than three-quarters of the collected bacterial isolates. These results are in line with previous findings that these CPS types are the dominant serotypes in different European countries as well as in the USA, whereas serotypes VI-IX have rarely been described (Wen-Tsung et al., 2014). Among our strains, CPS type III predominated in both invasive $(58.8 \%)$ and non-invasive $(28.6 \%)$ study groups. Overall, the most common clone identified was CPS III/ST17. The same clone dominated among LOD cases, whereas the welldescribed genotype Ia/ST23, prevailed among EOD. This observation is consistent with data from other regions in Europe (Poyart et al., 2008). Both clones, CPS III/ST17 and Ia/ST23 were also the most prevalent among invasive isolates in Italy (Gherardi et al., 2007). This overrepresentation of ST17 among invasive neonatal strains, particularly in LOD, is well recognized worldwide and highlights the fact that this clone is well adapted to human neonates (Imperi et al., 2011; Poyart et al., 2008). The GBS hyper-virulent adhesin ( $h v g A)$ specific for the hyper-virulent clone ST17 was found to mediate GBS adherence to intestinal epithelial cells, choroid epithelial cells, and microvascular endothelial cells (Tazi et al., 2010). HvgA thus contributes to colonization as well as invasion of hyper-virulent clones (Tazi et al., 2010). The ST17 clone is also described as a common cause of bone and joint infections (Law et al., 2017). However, only three cases of infants arthritis were observed in the present study. Only one of them was GBS type III/ST17. At least three major lineages of GBS isolates of serotype III (ST17, ST23 and ST19) were found in this study. ST19/serotype III has been reported as the predominant noninvasive clone among adults in the USA (Manning et al., 2008). Some European countries, like France, saw the emergence of serotype IV among GBS isolates (Bellais et al., 2012). It has already been confirmed that this emergence was due to a switching from $\mathrm{CC} 17$ hyper-virulent CPS type III to CPS type IV (Bellais et al., 2012). Sequence analysis revealed that this switch was due to the exchange of a 35.5-kb DNA fragment containing the entire cps operon (Bellais et al., 2012). Capsular switching is thought to contribute to the rise of new serotype-genotype 
combinations, allowing evasion of immune pressure (Martins et al., 2010). Hence, capsular switching in GBS CC17 hyper-virulent clone is a future challenge for polysaccharide vaccine development. In the present study, 12 GBS strains with capsular type IV were found, only one being ST17. Further investigation could decipher the genetic evolution of this particular GBS genotype (IV/ST17) in Serbia and investigate the rate of the previously described replacement of type III by a type IV cps locus. The highest diversity of GBS was found in strains of CPS types Ib, II and IV, while isolates of CPS III displayed the highest homogeneity, which is consistent with the clonal spread of the hyper-virulent genotype III/ST17.

Although worrying reports describing the emergence of clinical GBS isolates with reduced susceptibility to penicillin have been published, such GBS isolates were not detected in this study, and penicillin remains the drug of choice for IAP in GBS colonized pregnant women (Kimura et al., 2008). Increasing rates of resistance to erythromycin and clindamycin have been detected in several regions of the world, including Europe (Gherardi et al., 2007). Although a subtle increase in macrolide resistance among invasive GBS was reported, the resistance rate to erythromycin found in our study was comparable to those reported in other European studies (Florindo et al., 2010). Subsequently, it was demonstrated that erythromycin resistance is highly associated with CPS type V and III (Tazi et al., 2011; Joubrel et al., 2015). Our results confirm that macrolide resistance is not equally distributed among the GBS genotypes. Indeed, in the present study, resistance to erythromycin was strongly associated with CPS V, as it has already been reported (Gherardi et al., 2007). Additionally, the relation between erythromycin resistance and type III/ST19 has been recently described in Portugal (Florindo et al., 2010). This association was also observed in the present study in three non-invasive GBS isolated from adults. The majority of erythromycin-resistant GBS were co-resistant to clindamycin as well. Being the second-line antibiotic for penicillin-allergic patients, clindamycin resistance has important therapeutic implications, in particular when treatment is given empirically.

In conclusion, this first epidemiological report and genotypic diversity study of GBS isolates in Serbia suggests that circulating GBS belong to a limited number of genetic lineages. Overall, the most common genotypes circulating in Serbia were III/ST17 and V/ST1. Penicillin remains the antibiotic of choice for intrapartum GBS prophylaxis and susceptibility to macrolides must be tested in case of beta-lactam hypersensitivity. Implementation of continuous surveillance of GBS infections will be essential to assess GBS epidemiology and develop accurate GBS 
prevention strategies in Serbia. Further epidemiological studies are needed for getting better insight in GBS clones distribution, and for the subsequent development of future vaccination strategies.

\section{Funding}

This study was supported by the Federation of European Microbiological Societies [FEMSRG-2014-0025.R1] and the Serbian Ministry of Education and Science [Project No175039].

\section{Acknowledgements}

We gratefully acknowledge the following persons for supplying the strains used in this study: Marina Stojkovic, Snezana Tomanovic, Zorica Vasiljevic, Zlatica Cakic, Slobodanka Stefanovic, Suzana Laban Nestorovic, and Snezana Jovanovic.

\section{References}

1. Barrangou, R., Marraffini, L.A., 2014. CRISPR-Cas systems: prokaryotes upgrade to adaptive immunity. Mol Cell. 54, 234-244. https://doi: 10.1016/j.molcel.2014.03.011.

2. Bellais, S., Six, A., Fouet, A., Longo, M., Dmytruk, N., Glaser, P., Trieu-Cuot, P., Poyart, C., 2012. Capsular switching in group B Streptococcus CC17 hypervirulent clone: a future challenge for polysaccharide vaccine development. J Infect Dis. 206, 1745-1752. https://doi: 10.1093/infdis/jis605.

3. Bliss, S.J., Manning, S.D., Tallman, P., Baker, C.J., Pearlman, M.D., Marrs, C.F., Foxman, B., 2002. Group B Streptococcus colonization in male and nonpregnant female university students: a cross-sectional prevalence study. Clin Infect Dis. 34, 184-190. https://doi: 10.1086/338258.

4. Clinical and Laboratory Standards Institute. Performance standards for antimicrobial susceptibility testing. Twenty-Fourth informational supplement M100-S24. Wayne, PA: Clinical and Laboratory Standards Institute; 2014.

5. Compain, F., Hays, C., Touak, G., Dmytruk, N., Trieu-Cuot, P., Joubrel, C., Poyart, C., 2014. Molecular characterization of Streptococcus agalactiae isolates harboring small erm(T)-carrying plasmids. Antimicrob Agents Chemother. 58, 6928-6930. https://doi: 10.1128/AAC.03855-14.

6. Edmond, K.M., Kortsalioudaki, C., Scott, S., Schrag, S.J., Zaidi, A.K., Cousens, S., Heath, P.T., 2012. Group B streptococcal disease in infants aged younger than 3 
months: systematic review and meta-analysis. Lancet. 379, 547-556. https://doi: 10.1016/S0140-6736(11)61651-6.

7. Edwards, M.S., Nizet, V., Baker, C.J., 2011. Group B streptococcal infections, p 419469. In Remington JS, Klein JO, Wilson CB, Nizet V, Maldonado YA (eds.), Infectious Diseases of the Fetus and Newborn Infant. Elsevier, Philadelphia.

8. Edwards, M.S., Baker, C.J., 2005. Group B streptococcal infections in elderly adults. Clin Infect Dis. 41, 839-847. https://doi: 10.1086/432804.

9. Florindo, C., Viegas, S., Paulino, A., Rodrigues, E., Gomes, J.P., Borrego, M.J., 2010. Molecular characterization and antimicrobial susceptibility profiles in Streptococcus agalactiae colonizing strains: association of erythromycin resistance with subtype III-1 genetic clone family.Clin Microbiol Infect. 16, 1458-1463. https://doi: 10.1111/j.1469-0691.2009.03106.x.

10. Gherardi, G., Imperi, M., Baldassarri, L., Pataracchia, M., Alfarone, G., Recchia, S., Orefici, G., Dicuonzo, G., Creti, R., 2007. Molecular epidemiology and distribution of serotypes,surface proteins, and antibiotic resistance among group B streptococci in Italy. Journal of clinical microbiology. 45, 2909-2916. https://doi: 10.1128/JCM.00999-07.

11. Grissa, I., Vergnaud, G., Pourcel, C, 2007. The CRISPRdb database and tools to display CRISPRs and to generate dictionaries of spacers and repeats. BMC Bioinformatics. 23, 172-172. https://doi: 10.1186/1471-2105-8-172.

12. Gygax, S.E., Schuyler, J.A., Kimmel, L.E., Trama, J.P., Mordechai, E., Adelson, M.E., 2006. Erythromycin and clindamycin resistance in group B streptococcal clinical isolates. Antimicrob Agents Chemother. 50, 1875-1877. https://doi: 10.1128/AAC.50.5.1875-1877.2006.

13. Imperi, M., Gherardi, G., Berardi, A., Baldassarri, L., Pataracchia, M., Dicuonzo, G., Orefici, G., Creti, R., 2011. Invasive neonatal GBS infections from in area-based surveillance study in Italy. Clin Microbiol Infect. 17, 1834-1839. https://doi: 10.1111/j.1469-0691.2011.03479.x.

14. Jones, N., Bohnsack, J.F., Takahashi, S., Oliver, K.A., Chan, M.S., Kunst. F., Glaser, P., Rusniok, C., Crook, D.W., Harding, R.M., Bisharat, N., Spratt, B.G., 2003. Multilocus sequence typing system for group B streptococcus. J Clin Microbiol. 41, 2530-2536.

15. Joubrel, C., Tazi, A., Six, A., Dmytruk, N., Touak, G., Bidet, P., Raymond, J., Trieu Cuot, P., Fouet, A., Kernéis, S., Poyart, C., 2015. Group B Streptococcus neonatal invasive infections, France 2007-2012.Clin Microbiol Infect. 21, 910-916. https://doi: 10.1016/j.cmi.2015.05.039.

16. Kimura, K., Suzuki, S., Wachino, J., Kurokawa, H., Yamane, K., Shibata, N., Nagano, N., Kato, H., Shibayama, K., Arakawa, Y., 2008. First molecular characterization of group B streptococci with reduced penicillin susceptibility. Antimicrob Agents Chemother. 52, 2890-2897. https://doi: 10.1128/AAC.00185-08. 
17. Lamy, M.C., Dramsi, S., Billoet, A., Réglier-Poupet, H., Tazi, A., Raymond, J., Guérin, F., Couvé, E., Kunst, F., Glaser, P., Trieu-Cuot, P., Poyart, C., 2006. Rapid detection of the "highly virulent" group B Streptococcus ST-17 clone. Microbes Infect. 8, 1714-1722. https://doi: 10.1016/j.micinf.2006.02.008.

18. Law, G.W., Wijaya, L., Chye Tan, A.H., 2017. Group B Streptococcal prosthetic knee joint infection linked to the consumption of raw fish. J Orthop Case Rep. 7, 5457. https://doi: 10.13107/jocr.2250-0685.850.

19. Lopez-Sanchez, M.J., Sauvage, E., Da Cunha, V., Clermont, D., Ratsima Hariniaina, E., Gonzalez-Zorn, B., Poyart, C., Rosinski-Chupin, I., Glaser, P., 2012. The highly dynamic CRISPR1 system of Streptococcus agalactiae controls the diversity of its mobilome. Mol Microbiol. 85, 1057-1071. https://doi: 10.1111/j.13652958.2012.08172.x.

20. Manning, S.D., Lewis, M.A., Springman, A.C., Lehotzky, E., Whittam, T.S., Davies, H.D., 2008. Genotypic diversity and serotype distribution of group B Streptococcus isolates from women before and after delivery. Clin Infect Dis. 46, 1829-1837. https://doi: 10.1086/588296.

21. Martins, E.R., José Melo-Cristino, J., Ramirez M., 2010. Evidence for rare capsular switching in Streptococcus agalactiae. J Bacteriol. 192, 1361-1369. https://doi: 10.1128/JB.01130-09.

22. Poyart, C., Jardy, L., Quesne, G., Berche, P., Trieu-Cuot, P., 2003. Genetic basis of antibiotic resistance in Streptococcus agalactiae strains isolated in a French hospital. Antimicrob Agents Chemother. 47, 794-797.

23. Poyart, C., Réglier-Poupet, H., Tazi, A., Billoët, A., Dmytruk, N., Bidet, P., Bingen, E., Raymond, J., Trieu-Cuot, P., 2008. Invasive group B streptococcal infections in infants, France. Emerg Infect Dis. 14, 1647-1649. https://doi: 10.3201/eid1410.080185.

24. Poyart, C., Tazi, A., Réglier-Poupet, H., Billoët, A., Tavares, N., Raymond, J., TrieuCuot, P., 2007. Multiplex PCR assay for rapid and accurate capsular typing of group B streptococci. J Clin Microbiol. 45, 1985-1988. https://doi: 10.1128/JCM.00159-07.

25. Revised Guidelines from Center for Disease Control. 2010; 59 Prevention of perinatal group B streptococcus disease: a public health perspective, Morbidity and Mortality Weekly Report.

26. Seppa“la," H., Nissinen, A., Yu, Q., Huovinen, P., 1993. Three different phenotypes of erythromycin-resistant Streptococcus pyogenes in Finland. J Antimicrob Chemother. 32, 885-891.

27. Simpson, E.H., 1949. Measurement of diversity. Nature. 163, 688.

28. Slotved, H.C., Kong, F., Lambertsen, L., Sauer, S., Gilbert, G.L., 2007. Serotype IX, a proposed new Streptococcus agalactiae serotype. J Clin Microbiol. 45, 2929-2936. https://doi: 10.1128/JCM.00117-07. 
29. Sorek, R., Kunin, V., Hugenholtz, P., 2008. CRISPR - a widespread system that provides acquired resistance against phages in bacteria and archaea. Nat Rev Microbiol. 6, 181-186. https://doi: 10.1038/nrmicro1793.

30. Tazi, A., Disson, O., Bellais, S., Bouaboud, A., Dmytruk, N., Dramsi, S., Mistou, M.Y., Khun, H., Mechler, C., Tardieux, I., Trieu-Cuot, P., Lecuit, M., Poyart, C., 2010. The surface protein $H v g A$ mediates group B streptococcus hypervirulence and meningeal tropism in neonates. J Exp Med. 207, 2313-22. https://doi: 10.1084/jem.20092594.

31. Tazi, A., Morand, P.C., Réglier-Poupet, H., Dmytruk, N., Billoët, A., Antona, D., Trieu-Cuot, P., Poyart, C., 2011. Invasive group B streptococcal infections in adults, France (2007-2010). Clin Microbiol Infect. 17, 1587-1589. https://doi: 10.1111/j.1469-0691.2011.03628.x.

32. Walkenburg-van den Berg, A.W., Sprij, A.J., Oostvogel, P.M., Mutsaers, J.A.E.M., Renes, W.B. Rosendaal, F.R. Dorr, P.Joep., 2006. Prevalence of colonisation with group B Streptococci in pregnant women of a multi-ethnic population in the Netherlands. Eur J Obstet Gynecol Reprod Biol. 124, 178-183. https://doi: 10.1016/j.ejogrb.2005.06.007.

33. Wen-Tsung, L., Mei-Chin, L., 2015. High prevalence of Streptococcus agalactiae from vaginas of women in Taiwan and its mechanisms of macrolide and quinolone resistance. J Microbiol Immunol Infect. 48, 510-516. https://doi: 10.1016/j.jmii.2014.03.002. 
FIGURE 1. Correlation of clustered regularly interspaced short palindromic repeats 1 (CRISPR1) profiles, sequence types (STs) and capsular types of 90 invasive and noninvasive Streptococcus agalactiae isolated in Serbia

Graphic representation of CRISPR1 locus diversity in 90 Streptococcus agalactiae strains in the different capsular types. For clarity, the direct repeat sequences have been removed and only the spacer arrangements are represented. Spacers are shown as squares. Each unique spacer is represented on a white background; identical spacers are represented using similar-coloured backgrounds and identical numbers. The direction of the spacers is shown 5'-3', with respect to the leader. The last spacer acquired is represented on the left side while the first spacer is on the right side (ancestral end). Strains are listed by capsular type, ST, name, and spacer content of the CRISPR1 array. 
TABLE 1. Distribution of 432 Streptococcus agalactiae isolates among patient groups and specimens

Noninvasive strains: $\mathbf{N}$

Invasive strains: $\mathbf{N}$

\begin{tabular}{|c|c|c|c|c|c|c|c|}
\hline Patient group & $\begin{array}{c}\text { genital } \\
\text { specimen }\end{array}$ & $\begin{array}{c}\text { gastric } \\
\text { fluid }\end{array}$ & $\begin{array}{c}\text { nasopharyngeal } \\
\text { aspirate }\end{array}$ & & blood & CSF & $\begin{array}{l}\text { joint } \\
\text { fluid }\end{array}$ \\
\hline \multirow{3}{*}{ Children } & \multirow{3}{*}{2} & \multirow{3}{*}{3} & \multirow{3}{*}{1} & EOD & 20 & 1 & 1 \\
\hline & & & & LOD & 17 & 3 & 3 \\
\hline & & & & other & 1 & 1 & 1 \\
\hline Non-pregnant adults & 190 & 1 & 1 & & 6 & 1 & 1 \\
\hline Pregnant women & 185 & 1 & 1 & & 1 & 1 & 1 \\
\hline Total & 377 & 3 & 1 & & 44 & 4 & 3 \\
\hline
\end{tabular}

EOD, early-onset disease

LOD, late-onset disease 
TABLE 2. Distribution of capsular types and Multilocus Sequence Types among 101 randomly selected invasive and noninvasive Streptococcus agalactiae isolated from children and adults in Serbi

\begin{tabular}{|c|c|c|c|c|c|c|c|c|c|c|}
\hline \multirow{3}{*}{$\begin{array}{c}\text { Capsular } \\
\text { type }\end{array}$} & \multirow{3}{*}{ ST } & \multicolumn{6}{|c|}{ Invasive strains: $\mathbf{N}(\%)$} & \multicolumn{3}{|c|}{ Non-invasive strains: $\mathbf{N}(\%)$} \\
\hline & & \multirow[t]{2}{*}{ Total } & \multicolumn{3}{|c|}{ Children } & \multirow[t]{2}{*}{ Adults } & \multirow[t]{2}{*}{ Total } & \multirow[t]{2}{*}{ Children } & \multicolumn{2}{|c|}{ Adults } \\
\hline & & & EOD & LOD & $\begin{array}{c}>180 \\
\text { days old }\end{array}$ & & & & $\begin{array}{l}\text { pregnant } \\
\text { women }\end{array}$ & $\begin{array}{c}\text { non-pregnant } \\
\text { adults }\end{array}$ \\
\hline Ia & 23 & 4 & $4(44.4)$ & l & & & 11 & $2(40)$ & $4(11.8)$ & $5(14.3)$ \\
\hline \multirow[t]{5}{*}{$\mathrm{Ib}$} & 1 & & / & / & & & 1 & $1(20)$ & & \\
\hline & 3 & 1 & $1(11.1)$ & / & & & & & & \\
\hline & 8 & 3 & $1(11.1)$ & $1(6.7)$ & & $1(50)$ & 5 & & $4(11.8)$ & $1(2.9)$ \\
\hline & 6 & & & & & & 1 & & & $1(2.9)$ \\
\hline & 255 & & l & l & & & & & & \\
\hline \multirow[t]{5}{*}{ II } & 4 & & / & / & & & 1 & & $1(2.9)$ & \\
\hline & 10 & & / & / & & & 2 & & $1(2.9)$ & $1(2.9)$ \\
\hline & 12 & & / & / & & & 1 & & & $1(2.9)$ \\
\hline & 22 & & / & / & & & 1 & & $1(2.9)$ & \\
\hline & 28 & & / & / & & & 3 & & $1(2.9)$ & $2(5.7)$ \\
\hline \multirow[t]{5}{*}{ III } & 6 & & / & I & & & 1 & & & $1(2.9)$ \\
\hline & 8 & & I & I & & & 1 & & & $1(2.9)$ \\
\hline & 17 & 16 & $1(11.1)$ & $14(93.3)$ & $1(100)$ & & 10 & $1(20)$ & $7(20.6)$ & $2(5.7)$ \\
\hline & 19 & 1 & 1 & I & & $1(50)$ & 5 & & $1(2.9)$ & $4(11.4)$ \\
\hline & 23 & 1 & $1(11.1)$ & I & & & 9 & $1(20)$ & $4(11.8)$ & $4(11.4)$ \\
\hline \multirow[t]{2}{*}{ IV } & 1 & & 1 & / & & & 1 & & & $1(2.9)$ \\
\hline & 2 & 1 & $1(11.1)$ & I & & & & & & \\
\hline \multirow[t]{3}{*}{$\mathrm{V}$} & 1 & & 1 & I & & & 18 & & $7(20.6)$ & $11(31.4)$ \\
\hline & 19 & & I & / & & & 2 & & $2(5.9)$ & \\
\hline & 23 & & & & & & 1 & & $1(2.9)$ & \\
\hline Total & & $27(100)$ & $9(100)$ & $15(100)$ & $1(100)$ & $2(100)$ & 74 (100) & $5(100)$ & $34(100)$ & $35(100)$ \\
\hline
\end{tabular}

EOD, early-onset disease, LOD, late-onset disease ST, sequence type 
TABLE 3. Genetic diversity of 101 randomly selected Streptococcus agalactiae strains isolated in Serbia calculated by Simpsons indices of diversity according to the number of CRISPR1 profiles within a capsular type

\begin{tabular}{|c|c|c|c|c|}
\hline $\begin{array}{l}\text { Capsular } \\
\text { type }\end{array}$ & $\begin{array}{c}\text { MLST genetic } \\
\text { lineages (STs): } \mathbf{N}(\%)\end{array}$ & $\begin{array}{c}\text { Number of } \\
\text { CRISPR1 profiles }\end{array}$ & $\begin{array}{l}\text { Index of } \\
\text { diversity }\end{array}$ & $\begin{array}{l}\text { Number of } \\
\text { strains }(\%)\end{array}$ \\
\hline Ia & ST23: 15 (14.9) & 14 & 0.99 & $15(14.9)$ \\
\hline \multirow{4}{*}{ Ib } & ST8: 8 (7.9) & \multirow{4}{*}{11} & \multirow{4}{*}{1.00} & \multirow{4}{*}{$11(10.9)$} \\
\hline & ST3: 1 (1) & & & \\
\hline & ST1: 1 (1) & & & \\
\hline & ST255: $1(1)$ & & & \\
\hline \multirow{5}{*}{ II } & ST28: 3 (3) & \multirow{5}{*}{8} & \multirow{5}{*}{1.0} & \multirow{5}{*}{$8(7.9)$} \\
\hline & ST10: 2 (2) & & & \\
\hline & ST4: 1 (1) & & & \\
\hline & ST10: 1 (1) & & & \\
\hline & ST12: 1 (1) & & & \\
\hline \multirow{5}{*}{ III } & ST17: $26(25.7)$ & \multirow{5}{*}{35} & \multirow{5}{*}{0.97} & \multirow{5}{*}{$44(42.6)$} \\
\hline & ST23: $10(9.9)$ & & & \\
\hline & ST19: $6(5.9)$ & & & \\
\hline & ST6: 1 (1) & & & \\
\hline & ST8: 1 (1) & & & \\
\hline \multirow[t]{2}{*}{ IV } & ST1: $1(1)$ & \multirow[t]{2}{*}{2} & \multirow[t]{2}{*}{1.0} & \multirow[t]{2}{*}{$2(2)$} \\
\hline & ST2: 1 (1) & & & \\
\hline \multirow[t]{2}{*}{$\mathbf{V}$} & ST1: $19(18.8)$ & \multirow[t]{2}{*}{20} & \multirow[t]{2}{*}{0.995} & \multirow[t]{2}{*}{$21(20.8)$} \\
\hline & ST19: 2 (2) & & & \\
\hline
\end{tabular}

MLST, multilocus sequence typing

CRISPR, clustered regularly interspaced short palindromic repeats 
TABLE 4. Distribution of antimicrobial resistance genes within GBS capsular types

\begin{tabular}{|c|c|c|c|c|c|c|c|c|}
\hline $\begin{array}{c}\text { Capsular } \\
\text { type }\end{array}$ & $\begin{array}{c}\text { Number of } \\
\text { strains }\end{array}$ & $\begin{array}{c}\operatorname{erm} A \\
\mathrm{~N}(\%) \\
\end{array}$ & $\begin{array}{l}e r m B \\
\mathrm{~N}(\%)\end{array}$ & $\begin{array}{c}\text { mef } A \\
\text { N }(\%)\end{array}$ & $\begin{array}{c}\text { tetM } \\
\mathrm{N}(\%)\end{array}$ & $\begin{array}{c}\text { teto } \\
\mathrm{N}(\%)\end{array}$ & $\begin{array}{c}\text { tetL } \\
\mathbf{N}(\%)\end{array}$ & $\begin{array}{r}\operatorname{aph} A 3^{\prime} \\
\text { N }(\%)\end{array}$ \\
\hline Ia & 60 & $1(1.7)$ & & $8(13.3)$ & $50(83.3)$ & $6(10)$ & & \\
\hline Ib & 51 & & $5(9.8)$ & & $43(84.3)$ & & & \\
\hline II & 61 & $1(1.6)$ & $5(8.2)$ & & $47(77)$ & $9(14.8)$ & & \\
\hline III & 139 & $13(9.4)$ & $18(12.9)$ & $4(2.9)$ & $98(70.5)$ & $23(16.5)$ & $1(0.7)$ & $1(0.7)$ \\
\hline IV & 12 & $1(8.3)$ & $1(8.3)$ & & $10(3.3)$ & $1(8.3)$ & & \\
\hline $\mathbf{V}$ & 109 & $9(8.3)$ & $33(30.3)$ & & $80(73.4)$ & $9(8.3)$ & & \\
\hline
\end{tabular}




\begin{tabular}{|c|c|c|c|c|c|c|c|}
\hline apsular type & & & & & & & \\
\hline III & 17 & Serbie120 & & 822 & 254 & 101 & 102 \\
\hline III & 17 & Serbie150 & & 822 & 254 & 101 & 102 \\
\hline III & 17 & Serbie181 & & 822 & 254 & 101 & 102 \\
\hline III & 17 & Serbie45 & & 822 & 254 & 101 & 102 \\
\hline III & 17 & Serbie49 & & 822 & 254 & 101 & 102 \\
\hline III & 17 & Serbie51 & & 822 & 254 & 101 & 102 \\
\hline III & 17 & Serbie98 & & 822 & 254 & 101 & 102 \\
\hline III & 17 & Serbie48 & & 822 & 254 & 101 & 102 \\
\hline III & 17 & Serbie32 & & & 254 & 101 & 102 \\
\hline III & 17 & Serbie33 & & & 254 & 101 & 102 \\
\hline III & 17 & Serbie36 & & & 254 & 101 & 102 \\
\hline III & 17 & Serbie130 & 99 & 100 & & 101 & 102 \\
\hline III & 17 & Serbie114 & & 100 & & 101 & 102 \\
\hline III & 17 & Serbie50 & & 1205 & 243 & 101 & 102 \\
\hline III & 17 & Serbie113 & & & 243 & 101 & \\
\hline III & 17 & Serbie52 & & 823 & 243 & 101 & 102 \\
\hline III & 17 & Serbie31 & 812 & 49 & & 101 & 102 \\
\hline III & 17 & Serbie87 & & 822 & 254 & & 102 \\
\hline III & 17 & Serbie132 & & 822 & 254 & 101 & 254 \\
\hline III & 17 & Serbie63 & & & 254 & 101 & 102 \\
\hline III & 17 & Serbie46 & & 286 & & 101 & 102 \\
\hline III & 17 & Serbie5 & & & 254 & 101 & \\
\hline III & 17 & Serbie117 & & & 254 & 101 & \\
\hline III & 17 & Serbie38 & 281 & 282 & 283 & 288 & 291 \\
\hline III & 17 & Serbie122 & 268 & 269 & 72 & 73 & 74 \\
\hline III & 17 & Serbie55 & & 175 & 72 & 73 & 74 \\
\hline III & 23 & Serbie109 & & & & & \\
\hline III & 23 & Serbie61 & & & & & \\
\hline III & 23 & Serbie77 & & & & & \\
\hline III & 23 & Serbie111 & & & & & \\
\hline III & 23 & Serbie167 & & & & & \\
\hline III & 23 & Serbiego & & & & & \\
\hline III & 23 & Serbie78 & & & & & \\
\hline III & 23 & Serbie124 & & & & & \\
\hline III & 19 & Serbie27 & & & 676 & & \\
\hline III & 19 & Serbie41 & & & 126 & 1245 & 1246 \\
\hline III & 19 & Serbie92 & & & 154 & 522 & 155 \\
\hline III & 19 & Serbie28 & & & 527 & 528 & 529 \\
\hline III & 19 & Serbie84 & & & & $0=0$ & \\
\hline III & 19 & Serbie72 & & & & & \\
\hline III & 6 & Serbie112 & & & 764 & 765 & 766 \\
\hline IV & 1 & Serbie67 & & & & & 155 \\
\hline $\mathrm{V}$ & 1 & Serbie71 & & & & & \\
\hline v & 1 & Serbie83 & & & & & \\
\hline v & 1 & Serbieg9 & & & & & \\
\hline v & 1 & Serbie29 & & & & & \\
\hline v & 1 & Serbie106 & & 715 & 716 & 717 & 1192 \\
\hline v & 1 & Serbie74 & & 715 & 716 & 717 & 1192 \\
\hline V & 1 & Serbie104 & & & & 717 & 1192 \\
\hline v & 1 & Serbie66 & & & & & \\
\hline V & 1 & Serbie115 & & & & & \\
\hline V & 1 & Serbie47 & & & & & \\
\hline v & 1 & Serbie108 & & & & & \\
\hline V & 1 & Serbie26 & & & & & \\
\hline v & 1 & Serbie133 & & & & & \\
\hline v & 1 & Serbie101 & & & & & \\
\hline V & 1 & Serbie103 & & & & & \\
\hline v & 1 & Serbie105 & & & & 312 & 313 \\
\hline V & 1 & Serbie93 & & & & & \\
\hline V & 19 & Serbie123 & & & & & \\
\hline V & 19 & Serbie97 & & & & 105 & 106 \\
\hline la & 23 & Serbie118 & 803 & 1065 & & & \\
\hline la & 23 & Serbie126 & & & & 673 & 46 \\
\hline la & 23 & Serbie30 & 462 & 463 & 464 & 465 & 466 \\
\hline la & 23 & Serbie34 & 803 & 1065 & & & \\
\hline la & 23 & Serbie119 & & & & 360 & 361 \\
\hline la & 23 & Serbie44 & 1014 & 1321 & 1146 & 1322 & \\
\hline la & 23 & Serbie80 & 803 & 1065 & & & \\
\hline la & 23 & Serbie75 & & & & & 466 \\
\hline la & 23 & Serbie79 & & & & & \\
\hline la & 23 & Serbie116 & 858 & 859 & & & \\
\hline la & 23 & Serbie70 & & & & 673 & 466 \\
\hline la & 23 & Serbie76 & & & & & \\
\hline la & 23 & Serbie82 & & & & & \\
\hline la & 23 & Serbie35 & 462 & 463 & 464 & 465 & \\
\hline la & 23 & Serbie88 & & & & & \\
\hline $\mathrm{Ib}$ & 8 & Serbie60 & & & & & \\
\hline $\mathrm{lb}$ & 8 & Serbie65 & 295 & 296 & 297 & 298 & 478 \\
\hline $\mathrm{lb}$ & 8 & Serbie59 & & & & & \\
\hline $\mathrm{Ib}$ & 8 & Serbie81 & & & & & \\
\hline $\mathrm{lb}$ & 8 & Serbie94 & 295 & 296 & 297 & & \\
\hline $\mathrm{lb}$ & 8 & Serbie42 & 295 & 296 & $297^{\circ}$ & 298 & \\
\hline $\mathrm{lb}$ & 8 & Serbie162 & & & & & \\
\hline $\mathrm{lb}$ & 8 & Serbie131 & 295 & & & & \\
\hline $\mathrm{lb}$ & 1 & Serbie91 & & & & & \\
\hline ॥ & 12 & Serbie121 & & & & & \\
\hline II & 10 & Serbie100 & & & & & \\
\hline$\|$ & 10 & Serbie128 & & & & & \\
\hline II & 28 & Serbie129 & & 664 & 665 & 666 & 369 \\
\hline II & 28 & Serbie24 & & 664 & 665 & 666 & 369 \\
\hline
\end{tabular}

Fig. 1 